\title{
TRAINING OF ASTRONOMERS IN CENTRAL ASIA AND SOME COMPARISONS
}

\author{
S. N. NURITDINOV \\ Astronomy Department, Tashkent State University, \\ Tashkent, Uzbekistan. e-mail root@tsu.silk.org
}

In the Soviet Union (SU) professional curricula were the same in each republic. After the dissolution of the SU the various states in the Commonwealth of Independent States gradually adopted quite different curricula. Some professions were narrowed in scope or were no longer provided for. Until recently there were, in Central Asia, three types of curricula for taining astronomers:

1) An "astronomy" curriculum in the Universities,

2) An "astrophysics" specialization within the "Physics" curriculum in the universities,

3) A "physics and astronomy" curriculum for future schoolteachers in the Teachers' Training Colleges.

Today in Central Asia, after perestroika only Tashkent State University trains astronomers. There was previously a chair of astrophysics in Tadjikistan State University, but it was discontinued a long time ago. In Kazakhstan and Kirgistan, astronomers are not trained at all. The system for training astronomers in different countries of the former SU now differs very much. For example, Uzbekistan and Lithuania use the multistep system (Bachelor, Master etc). Moscow University and many of the well-known universities of Russia and the Ukraine continue to use the old five-year system. That is why we are ready to invite would-be astronomers from neighbouring countries to tkae our bachelor's and master's courses. I will briefly describe our curricula.

The Astronomy Bachelor Curriculum has the structure shown in Table 1:

TABLE 1. The Bachelor's Curriculum

\begin{tabular}{lr}
\hline Blocks of Subjects & Planned Hours \\
\hline Astronomy and general education courses & 3534 \\
Social-humanitarian courses & 1836 \\
Mathematical and natural science courses & 614 \\
Elected special courses or astronomy & 544 \\
\hline
\end{tabular}

We give lectures for the bachelor's degree in the general and special astronomical subjects listed in Table 2.

In addition, we have begun to teach masters' courses also in two specialities, namely: (i) Astrophysics and Radioastronomy, (ii) Astrometry and Celestial Mechanics. The master's curriculum has the structure shown in Table 3.

In addition to their specialization, all master's students attend the following courses together: (i) Computer and Applied Astronomy, (ii) Television Astronomy, (iii) Modern Radiation Detectors in Astronony, (iv) Random Processes in Astronomy and the Theory of Errors, (v) Astronomy from above the Earth's Atmosphere. Separately, the two groups of students attend the courses shown in Table 4 .

Relying on our long and hard experience of creating these bachelor's and master's curricula, I would like to suggest that IAU Commission 46 should organize a meeting to discuss modern educational programmes. This could improve the level of modern astronomy education and would 
TABLE 2. Lecture Timetable

\begin{tabular}{lrlr}
\hline General Subjects & Planned Hours & Special Courses & Planned Hours \\
\hline General Astronomy & 122 & Solar Physics & 40 \\
General Astrophysics & 82 & Physics of Stars & 40 \\
General Astrometry & 74 & Extragalactic Astronomy & 40 \\
Theoretical Astrophysics & 51 & Theory of Spacecraft Motion & 38 \\
Celestial Mechanics & 94 & Elective Subject & 40 \\
Galactic Astronomy & 56 & Elective Subject & 40 \\
Numerical Analysis of Observational data & 32 & Special Labs & \\
Physics of Cosmic Space & 38 & \& Practical Astronomy 150 & \\
Computer Methods in Astronomy & 46 & & \\
Radioastronomy & 58 & & \\
History of Astronomy & 38 & & \\
\hline
\end{tabular}

TABLE 3. The Master's Curriculum

\begin{tabular}{lc}
\hline Kind of Activity & Number of Weeks \\
\hline Theoretical education & 33 \\
Scientific activity & 36 \\
Master's dissertation & 17 \\
Control of knowledge & 4 \\
\hline
\end{tabular}

particularly help the republics of the former SU to decide whether or ont to change to the BachelorMaster system. It would be good if Commission 46 could help to arrange grants for the purchase of new foreign books and jurnals on astronomy. Central Asia would be greatly helped if there could be an International Chair of astronomy (perhaps a UNESCO chair) in Tashkent. We also have courses of doctoral and post-doctoral education.

TABLE 4. Specialized Master's Courses

\begin{tabular}{|c|c|}
\hline Astrophysics \& Radio Astronomy & Astrometry \& Celestial Mechanics \\
\hline $\begin{array}{c}\text { Plasma Astrophysics } \\
\text { Structure of Astronomical Images } \\
\text { Astroclimate } \\
\text { Astrospectroscopy } \\
\text { Theory of Stellar Evolution } \\
\text { Helioseismology } \\
\text { Close Binary Systems } \\
\text { Solar-Terrestrial Physics } \\
\text { Cosmology } \\
\text { Physics of Interstellar Medium \& } \\
\text { Regions of Star Formation } \\
\text { Mechanisms of Radio-radiation } \\
\text { from Astrophysical Objects } \\
\text { Quasars and Active Galactic Nuclei }\end{array}$ & $\begin{array}{l}\text { Theory of Establishment of an } \\
\text { Inertial Coordinate System } \\
\text { Theory of Photographic Astronomy } \\
\text { Theory of Satellite \& Spacecraft Motion } \\
\text { Additional Chapters of Modern Astronomy } \\
\text { Additional Chapters of Celestial Mechanics } \\
\text { Planetary Astronnomy } \\
\text { Star Clusters } \\
\text { Investigations of the Earth from Space } \\
\text { Theory of Gravitational Potential }\end{array}$ \\
\hline
\end{tabular}

